\title{
An Urban Energy Atlas and Engineering Model for Resilient Cities
}

\author{
Guglielmina Mutani ${ }^{1 *}$, Valeria Todeschi ${ }^{2}$ \\ ${ }^{1}$ Politecnico di Torino, Department of Energy - R3C, C.so Duca degli Abruzzi, 24, Torino 10129, Italy \\ ${ }^{2}$ Politecnico di Torino, Department of Energy - FULL, C.so Duca degli Abruzzi, 24, Torino 10129, Italy
}

Corresponding Author Email: guglielmina.mutani@polito.it

https://doi.org/10.18280/ijht.370402

Received: 2 October 2019

Accepted: 10 November 2019

\section{Keywords:}

urban energy atlas, engineering model, energy efficiency, renewable energy sources, energy resilience, geographic information system

\begin{abstract}
Increasing energy efficiency in buildings is a crucial topic, especially in those EU countries where almost $50 \%$ of the final energy consumption is used for space heating and cooling, of which $80 \%$ is used for buildings. This study presents a model and a tool that can be used to evaluate energy consumption and to identify retrofitting strategies and renewable energy sources with the aim of reaching energy and climate targets in order to improve energy security, competitiveness and sustainability in a territory. In a previous research, a 'top-down engineering' model was applied for a number of $1 \mathrm{~km}^{2}$ districts in the city of Turin (IT) to evaluate the residual potential of buildings that could be connected to the district heating network. In this work, the energy-use model has been improved by considering applications to urban areas of different dimensions, and an urban energy atlas for the Turin building stock has been defined with the support of a Geographical Information System. The model has been validated by comparing the results of an energy balance calculation with energy consumption data of three consecutive heating seasons over an area of about $40 \mathrm{~km}^{2}$ in which 500,000 inhabitants live.
\end{abstract}

\section{INTRODUCTION}

According to the current European directives, the aim of energy policies, at regional, national and international levels, is to achieve energy and climate targets through an improvement of energy efficiency and a greater use of renewable energy sources [1]. This paper describes an energyuse model at a district scale and presents an application example that consists in the of an energy atlas for the evaluation of the distribution of consumptions within a city at different territorial scales. The main aim of this work is to present a 'top-down engineering' model, based on an energy balance (for space heating and domestic hot water), of a district considering a monthly time step. The energy model is based on standard heat transfer equations for a set of buildings; the novelty concerns the scale of the model, which considers a portion of the urban context and introduces the urban parameters that affect its energy performance [2].

The energy consumption of buildings is related to several factors, such as the construction and geometric characteristics [3], the occupancy and socio-economic aspects (i.e. economic growth) [4], the climate and microclimate conditions [5], solar exposure, and the urban morphology, while the interaction between buildings and the surrounding urban context should also be taken into consideration [6]. The presented modeling approach considers not only the characteristics of buildings, but also the features of the urban context that affect the energy performance of the buildings. This model introduces two urban variables - the 'sky view factor' and the urban canyon 'height-to-distance ratio' - to describe the solar exposition, the percentage of sunny surfaces and the thermal radiation lost to the sky [2]. This model can also be applied to critical highdensity urban contexts to promote energy security, a reduction in energy dependency from abroad and a sustainable future development. The balance between energy supply and demand can in particular be investigated by optimizing the heat distribution, for example, by considering a district heating network, and identifying critical areas where other energy efficiency measures could be more effective [6].

\subsection{Research gap}

Studies on Urban-Scale Energy Modeling (USEM) have shown the importance of morphological characteristics for the energy consumption of buildings [7]. The influence of urban form is considered important to optimize an energy system, together with the impact of the microclimate in built-up areas [8] and the characteristics of the outdoor environment [9]. These models also investigate the interaction between individual buildings and the urban context. USEM can be used to support policy makers and urban planners' decisions, and consequently play a key role in the definition and prediction of the effect of different energy efficiency strategies [10].

Geographic Information System (GIS) tools are fundamental for the creation of USEM models, to collect, manage and organize geographical data in order to evaluate the strengths and weaknesses of a territory [11]. GIS tools can also be used to create an atlas where data can be represented and the energy distribution, or other indicators, such as the energy consumptions, types of users, and the characteristics of the built environment, can be visualized on maps.

It can be deduced from the literature that there are two types of atlas, the 'urban atlas' and the 'energy atlas'. The 'urban atlas' describes land uses, the type of outdoor spaces and the morphological characteristics of built-up environments using several indicators, such as the sky view factor and the 
pavement cover ratio [12]. It is possible, with an urban atlas, to assess changes in the urbanized landscape and analyze, for example, the relationship between an urban microclimate and the urban morphological parameters at a district scale [13].

An 'energy atlas' is used to describe the distribution of energy consumption at a municipal or national scale [14], and two kind of atlas exist:

- the energy atlas, which evaluates the distribution of energy consumption using, for example, energy performance certificates, and analyzes the renovation level of buildings [14], points out the potentials energy savings $[15,16]$

- the energy atlas, which calculates the energy that can be produced from the available renewable energy sources (i.e. wind and solar PV and thermal collectors) $[17,18]$.

Therefore, an energy atlas should be a platform that plays a significant role in the planning of sustainable and smart energy systems at a territorial level, and which gives information on the analysis of aggregated energy consumptions rather than that of an individual building-level [18].

Cities are particularly vulnerable to the effects of climate change due to extreme weather conditions [19]. The concept of resilience is an important topic that should be considered to address the effects of climate change in order to improve energy security, affordability and sustainability [20] for the development of cities [21]. To achieve energy and climate targets, it is necessary to:

- improve the resilience of the city (which is frequently affected by climate change and weather extremes) in order to guarantee an affordable, reliable, sustainable and modern energy system from different points of view: energy, economic, environmental and social [22];

- $\quad$ promote energy efficiency measures [19] (i.e. building energy codes that can play an important role in energy savings [23]);

- $\quad$ exploit the renewable energy sources that are available locally [24].

In an investigation of energy resilience, it is essential not only to guarantee continuity in the supply of energy, but also to maintain the quality and quantity of the services for human activities. The question is: "how does a city respond to disturbances or non-linear dynamics"?

This work presents a useful tool for the analysis of the current conditions of a specific urban territory, which can identify the most vulnerable areas in which the energy system could have greater difficulties in readapting following shocks and disturbances. A new methodology will be investigated in a future research to evaluate future scenarios on the basis of how the energy system responds and adapts to disturbances, events or non-linear dynamics.

\subsection{Research objectives}

The objective of this study was to create an 'urban energy atlas' of the building stock of Turin to obtain information on the energy consumptions (for space heating and domestic hot water) and to identify critical energy-efficiency and lowcarbon priority areas at an urban level. The novelty of the presented atlas is that it adopts a 'top-down-engineering' model approach, based on a neighborhood-scale energy balance. The model has been validated considering the consumptions provided by the district heating DH Company. The thermal energy balance takes into account all the characteristics of a given urban environment, and the energy consumptions can be calculated at a building scale or, using aggregated data, at a neighborhood, district or municipal scale. Starting from the results of a previous research [25], this study explores the flexibility and the accuracy of the 'top-down engineering' model at different scales. The aim of this work has been to investigate the following matters:

- Is the monthly model set up in previous researches [25] flexible? How precise would the results be if the model were applied at a territorial scale, considering urban areas of different dimensions?

- How would the accuracy of the model change if some areas, with different characteristics from the field of application of the model, were included in the analysis?

The methodology used to simulate the monthly energy balance and to create an urban energy atlas is presented in the first part of this work (section 2). The case study and the input data are described in section 3 and mapped with a GIS tool. The results of the application of the engineering model at different scales are discussed in section 4 , and possible future improvements of the urban energy atlas are suggested.

\section{MATERIALS AND METHODS}

This paper presents a 'top-down engineering' model to evaluate the energy performance of buildings at an urban scale, using energy data measured by a DH Company. The model is designed for Italian cities with a very high concentration of residential buildings. For this reason, an engineering model has been used for the residential buildings and a model for archetypes for the other uses. In reality, the scarcity of consumption data for non-residential uses only allowed information on the specific consumption to be obtained for each type of buildings [26]. On the other hand, a model based on energy flows was created for residential buildings and the methodology that was adopted is based on a simplified version of the building energy model described in the ISO 520161:2017 and ISO 52017-1:2017 Standards. In order to take into account the urban context and the relationship between buildings and their surroundings in the energy balance model, a number of morphological parameters were added; only some information was available for the buildings at a territorial scale, and too much data would slow down the simulations. The main characteristics of residential buildings that influence their energy performance are: the surface-to-volume ratio, ' $\mathrm{S} / \mathrm{V}$ ', the period of construction, and the type and efficiency of the space heating $(\mathrm{H})$ and of the domestic hot water (DHW) systems [2]. After collecting the data, a georeferenced database was created at a territorial scale with the support of a GIS tool (ArcGIS 10.7) and urban areas with different dimensions were identified. In the second phase, the urban energy balance models were applied to a case study and the precision was assessed by comparing the measured data and the calculated data on areas with different dimensions. Finally, the results were visualized and an urban energy atlas was created with the support of GIS and Google Earth tools.

\subsection{The urban energy balance models}

The energy consumption of residential buildings was simulated. with a 'top-down engineering' model, using a monthly energy balance at a neighborhood scale, considering the sensible energy uses for space heating and domestic hot 
water. This model is based on simplified heat transfer equations, considering a monthly period, applied to a group of buildings, and it introduces two urban variables into the thermal balance that affect the consumption of buildings. The simulation of energy consumptions was carried out taking into account the variability of the external climatic conditions, the characteristics of the residential buildings and their surroundings, and (for the validation) the monthly data of energy consumptions that were available at a district scale. A group of buildings represents a thermodynamic system, and the heat and mass flows between the system and the outside environment are represented in Figure 1.

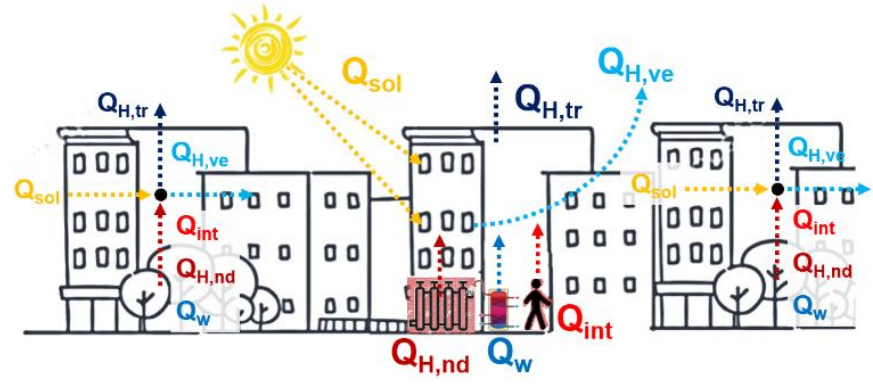

Figure 1. Scheme of the heat and mass flows of the thermodynamic system of the building stock at a neighborhood scale

The method used to calculate the monthly energy balance of residential buildings, at a neighborhood scale, refers to the ISO 52016 and 52017 Standards:

$$
\begin{aligned}
Q_{H, n d} & =\sum Q_{H, h t}-\eta_{H, g n} \cdot \sum Q_{g n}= \\
& =\left(\sum Q_{H, t r}+\sum Q_{H, v e}\right)-\eta_{H, g n} \cdot\left(\sum Q_{i n t}+\sum Q_{s o l}\right) \cdot(1)
\end{aligned}
$$

The total heat transfer $\left(\mathrm{Q}_{\mathrm{H}, \mathrm{ht}}\right)$ is composed of the sum of the heat transfer due to transmission and ventilation; the total heat gains $\left(\mathrm{Q}_{\mathrm{gn}}\right)$ is due to internal heat sources and solar components.

The heat transfer due to transmission $\left(Q_{H, t r}\right)$ was calculated considering the heat lost through the air temperatures gradient, the thermal radiation to the sky and the solar gains on the opaque envelope:

$Q_{H, t r}=H_{t r, a d j} \cdot\left(T_{i}-T_{e}\right) \cdot \tau+\left\{\sum_{k} F_{r, k} \cdot \phi_{r, k}\right\} \cdot \tau-Q_{\text {sol }, o p}$.

The transmission heat transfer coefficient $H_{t r, a d j}$ depends on:

- the thermal transmittances (U) of the building envelope, and the $U$ values were therefore identified for each district/urban area using the percentage of heated volume of residential buildings for each period of construction;

- the opaque and transparent heat dispersing areas (with a constant transparent area equal to $1 / 8$ of the building floor surface), which were calculated by summing the surfaces of each building;

- the unheated volumes of the attics and cellars.

The difference between the air temperature inside the heated buildings $\left(\mathrm{T}_{\mathrm{i}}\right)$ and the external air temperature $\left(\mathrm{T}_{\mathrm{e}}\right)$ affects the heat dispersions between the heated spaces of the buildings and the external environment; $\mathrm{T}_{\mathrm{i}}$ was assumed constant during the heating season $\left(20^{\circ} \mathrm{C}\right)$ and $\mathrm{T}_{\mathrm{e}}$ refers to the outdoor air temperature registered by the nearest weather stations (WS).

The extra heat transfer was calculated using the form factor between the building stock and the sky $\left(\mathrm{F}_{\mathrm{r}, \mathrm{k}}\right)$ and the thermal radiation lost to the sky $\left(\Phi_{\mathrm{r}}\right)$. The form factor, $\mathrm{F}_{\mathrm{r}, \mathrm{k}}$, depends on the characteristics of the built environment, and it was calculated using the sky view factor (SVF) of the building stock and the inclination $(\Sigma)$ of the control surface:

$$
F_{r, k}=F_{s h, o b} \cdot \frac{1-\cos \Sigma}{2}=\boldsymbol{S V F} \cdot \frac{1-\cos \Sigma}{2} .
$$

The solar heat gains through the opaque elements $\left(Q_{\text {sol,op }}\right)$ were calculated with:

$$
\begin{aligned}
Q_{\text {sol }, o p} & =\left\{\sum_{k} \phi_{\text {sol }, o p, k}\right\} \cdot \tau \\
\phi_{\text {sol }, o p, k} & =F_{\text {sh ob }, o p} \cdot A_{\text {sol }, o p} \cdot I_{\text {sol }, o p}= \\
& =\boldsymbol{\omega} \cdot \boldsymbol{S V} \boldsymbol{F} \cdot \frac{1-\cos \Sigma}{2} \cdot A_{\text {sol }, o p} \cdot I_{\text {sol }, o p} .
\end{aligned}
$$

In order to take into account the influence of the direct solar radiation component, $\Phi_{\text {sol,op }}$ was multiplied by the percentage of sunny surfaces $\omega$ calculated as a function of the average height of the sun $\beta$ (for each month) and of the urban canyon $\mathrm{H} / \mathrm{W}$ ratio (in Figure 2). Then, $\mathrm{F}_{\text {sh,ob,op }}$ is a function of the solar obstacles and, at urban scale, can be calculated using $\omega$ and SVF; the capturing opaque surface $\left(\mathrm{A}_{\text {sol,op }}\right)$ was calculated hypothesizing the color of the buildings envelope with the relative absorption coefficient $\left(\alpha_{\text {sol,op }}\right)$; finally, the incident solar irradiance $\left(I_{s o l, o p}\right)$ was calculated according to the climate data recorded by the WSs on the horizontal plane.

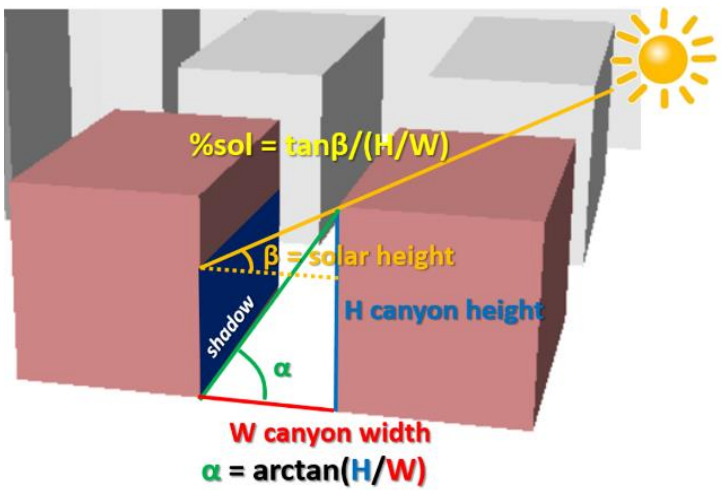

Figure 2. Evaluation of the percentage of sunny surfaces as a function of the solar height $(\beta)$ and the $\mathrm{H} / \mathrm{W}$ ratio

The ventilation heat losses $\left(Q_{H, v e}\right)$ were calculated using the heat transfer coefficient, which depends on the air flow rate or the hourly air exchange volumes that were defined by the type of buildings' user. According to UNI/TS 11300-1:2014 (issued to implement European Directive 2002/91/CE), the internal heat gains $Q_{i n t}$ were calculated considering the floor area of residential buildings and the average area per dwelling; for residential buildings with a net floor area $\left(S_{f}\right)$ less than or equal to $120 \mathrm{~m}^{2}$, the internal heat gains were obtained:

$$
Q_{\text {int }}=\left\{\sum_{k} \phi_{i n t, k}\right\} \cdot \tau=\left\{5.294 \cdot S_{f}-0.01577 \cdot S_{f}^{2}\right\} \cdot \tau .
$$

The solar heat gains $\left(Q_{s o l, w}\right)$ were calculated, according to Eq. (6) and (6.1), by multiplying the SVF by $\omega$ that considers the sunny percentage quota of the windows area (as mentioned above for the opaque component). The effective glazing area 
$\left(A_{s o l, w}\right)$ pertains to the window area, the window frame factor and the total solar energy transmittance of the glass $(g)$ identified with the percentage of the buildings with the different periods of construction:

$$
\begin{aligned}
Q_{s o l, w} & =\left\{\sum_{k} \phi_{s o l, w, k}\right\} \cdot \tau \\
\phi_{s o l, w, k} & =F_{s h, o b, w} \cdot A_{s o l, w} \cdot I_{s o l, w}= \\
& =\boldsymbol{\omega} \cdot \boldsymbol{S V} \boldsymbol{F} \cdot \frac{1-\cos \Sigma}{2} \cdot A_{s o l, w} \cdot I_{s o l, w} .
\end{aligned}
$$

The energy demand for domestic hot water $\left(Q_{D H W}\right)$ was calculated using: the percentage of buildings served by the DH network for this service (given by the DH Company), the required daily volume of hot water (as a function of the type of user and, for residential buildings, depends by the average floor area per dwelling), and the number of days for month.

Finally, once the efficiencies of the systems were known $(\eta)$, the energy consumptions were calculated as:

$$
Q_{H}=\frac{Q_{H, n d}}{\eta} ; \quad Q_{D H W}=\frac{Q_{D H W, n d}}{\eta} .
$$

Different system efficiencies were evaluated for the various periods of construction and considering the type of system: centralized, autonomous or centralized connected to the $\mathrm{DH}$ network [25].

The novelty of this model is that energy balance equations usually only consider the thermal balance of one building, while a group of buildings is considered in these models. Moreover, two urban parameters were added to adapt the energy balance to a neighborhood scale: the sky view factor (SVF) and the urban canyon height-to-distance ratio $(\mathrm{H} / \mathrm{W})$; these variables describe the solar exposition and the thermal radiation lost to the sky from the built environment; a further coefficient $(\omega)$ was introduced to define the percentage of sunny surfaces.

\subsubsection{Evaluation of the percentage of sunny surfaces}

A coefficient that considers the percentage of sunny surfaces was introduced to quantify the solar heat gains. Two methods can be used:

a) One method considers the average height and direction of the sun for each month (using a typical day of each month as a reference) and the canyon height-todistance ratio $\mathrm{H} / \mathrm{W}$ parameter calculated for each neighborhood;

b) Another method uses the Hillshade tool (with the support of ArcGIS 10.6), which creates a shaded relief from a surface raster by considering the illumination source angle and shadows.

In order to conduct this kind of analysis, the input data should refer to the average height and direction of the sun for each month, and a Digital Surface Model (DSM), with a precision of 0.5 meters, that takes into account the urban morphology of the built-up environment should be considered.

\subsection{The urban energy atlas at a territorial scale}

The process adopted to generate the energy consumption maps at different scales is presented (Figure 3) in this section. The procedure was subdivided into four phases: input data, elaboration data, urban-scale energy modeling and visualization. In the first phase, all the data necessary to simulate the space heating and domestic hot water consumptions were collected and elaborated (phase two) to create a georeferenced database at a district scale. Subsequently, the urban energy balance models were applied at a territorial scale considering urban areas of different dimensions. Starting from a neighborhood of $1 \mathrm{~km}^{2}$ (mesh), three application scales were identified by aggregating two or more districts (scales 1, 2 and 3). The aggregation was made using a GIS tool and considering different aspects: the spatial distribution, the characteristics of the built environment and socio-economic conditions, and the type of DH consumptions (only space heating or space heating plus domestic hot water). In the last phase, the results were visualized and an urban energy atlas was created for the city of Turin with the support of the Google Earth tool. These results will be discussed with the municipality of Turin to create an interactive WebGIS tool.

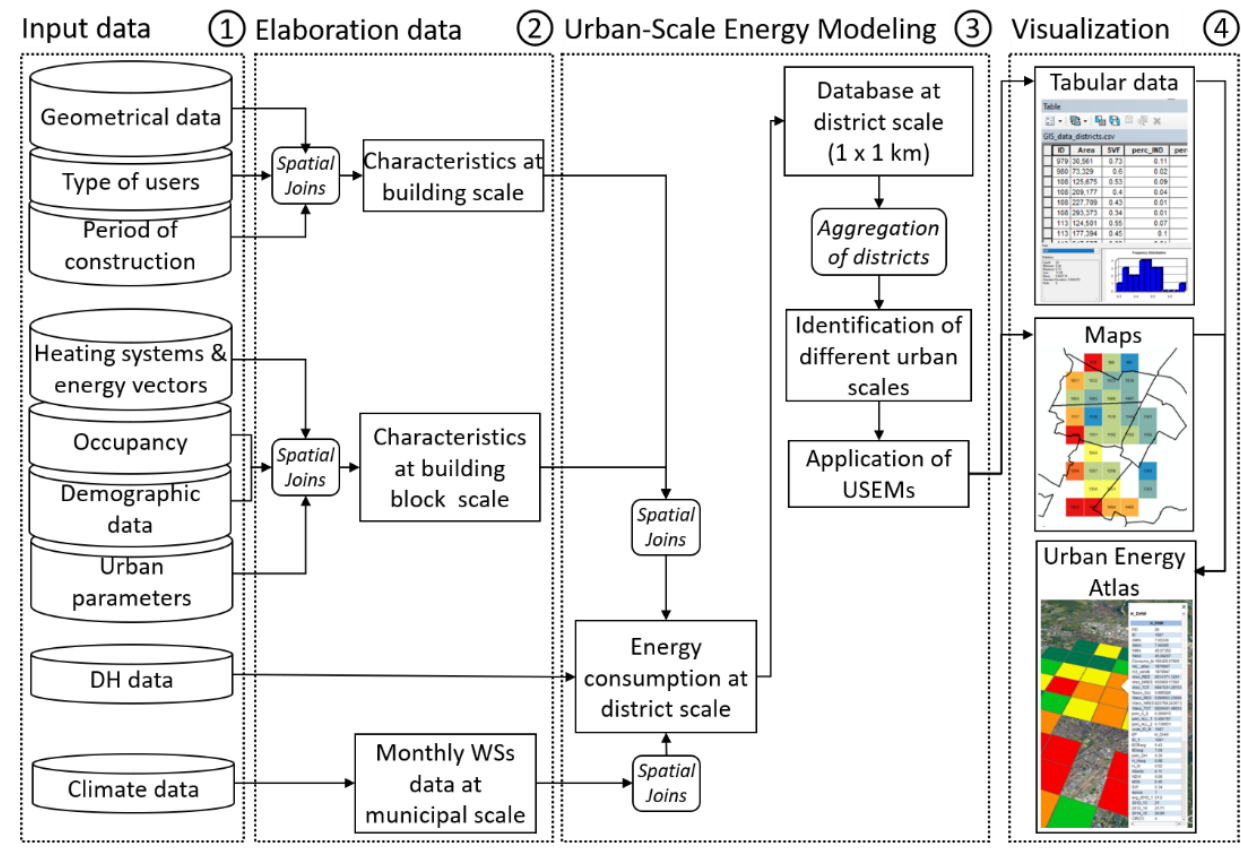

Figure 3. Flowchart of the urban energy atlas methodology 


\subsubsection{Urban-scale energy modeling}

The thermo-physical and geometric parameters of the residential buildings in the analyzed districts were characterized using information from the Municipal Technical Map (2015), the Territorial Database of the Region (2019), the socio-economic data (ISTAT census database 2011), weather station measurements, a Digital Surface Model (DSM) with a precision of 0.5 and 5 meters, European Standards, and data from literature reviews (i.e. TABULA [27]).

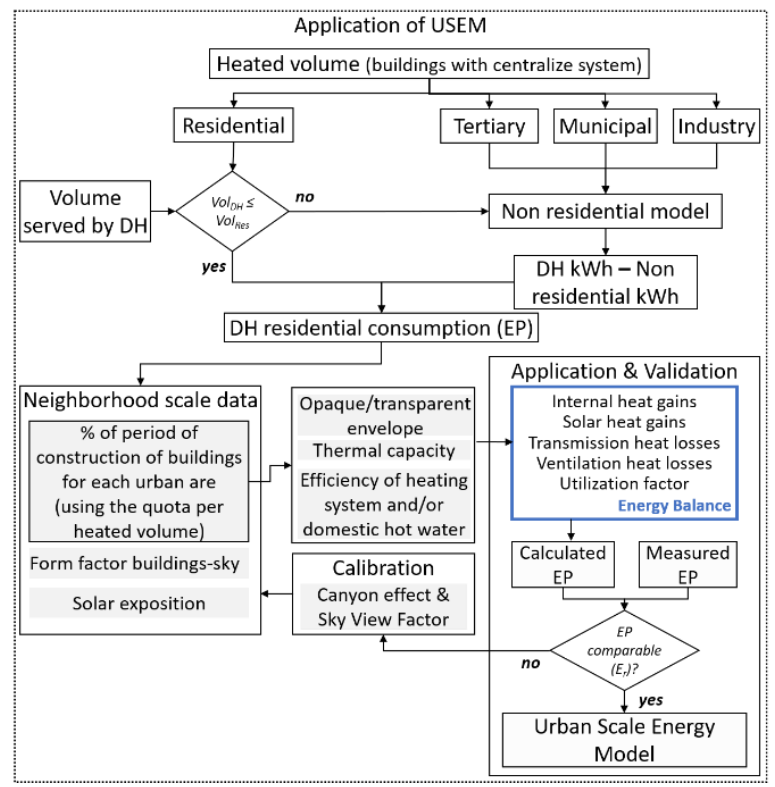

Figure 4. Flowchart for the evaluation of the urban-scale energy modeling

Figure 4 shows the methodology used to calculate the input data, at different scales, to simulate the $\mathrm{DH}$ consumption at a territorial scale. The input data were calculated for each urban area dimension (scales 0, 1, 2 and 3) to characterize the residential buildings connected to the DH network. Data concerning the geometric and construction characteristics of the building were calculated considering the percentage distribution of the buildings with different construction periods (modeling). The space heating and domestic hot water consumptions were simulated considering different urban area dimensions. The model was validated using the measured monthly consumptions of 48 different $1 \mathrm{~km}^{2}$ neighborhoods for three consecutive heating seasons (2012-13, 2013-14, 2014-15). The procedure that was used is outlined in Figure 5. The volumes connected to the DH network were compared with the residential quota. A specific energy consumption $\left(\mathrm{kWh} / \mathrm{m}^{3}\right)$ was attributed to non-residential buildings as a function of the type of use. The considered specific energy consumptions can be found in [26] (referring to an occupied volume and at $2221 \mathrm{HDD}$ at $20^{\circ} \mathrm{C}$ ). The consumption of only the residential buildings was then evaluated. A monthly energy balance was assumed for residential buildings, using different variables, until the calculated energy performance (EP) could be compared with the measured one. This validation was implemented considering the errors, relative errors and global errors for each heating season.

\section{CASE STUDY}

The urban energy balance model was applied to the city of
Turin (IT) and an urban energy atlas was created at a territorial scale with the support of GIS and Google Earth tools.

Turin is located in the North-Western part of Italy, and it has a continental, temperate climate (called zone E in Italy). The space heating and domestic hot water consumption of buildings in Turin is quite significant; this is partly due to the fact that most of residential buildings were built before the laws on buildings energy savings were introduced (about $80 \%$ of the buildings were built before 1976). There are about 60,000 heated buildings in Turin, of which 45,000 are residential (a number that is equal to $232 \mathrm{Mm}^{3}$ of the gross volume). The residential buildings are mainly large and compact condominiums, $55 \%$ of which have a surface-tovolume ratio (S/V) of less than $0.45 \mathrm{~m}^{2} / \mathrm{m}^{3}$ (the average value in Turin is $0.55 \mathrm{~m}^{2} / \mathrm{m}^{3}$ ). There are also historical and architectural constraints that limit energy retrofitting actions. Furthermore, the complex territory, which is surrounded by mountains and hills, and has parks, four rivers and large industrial areas, significantly influences the sustainable development of the city.

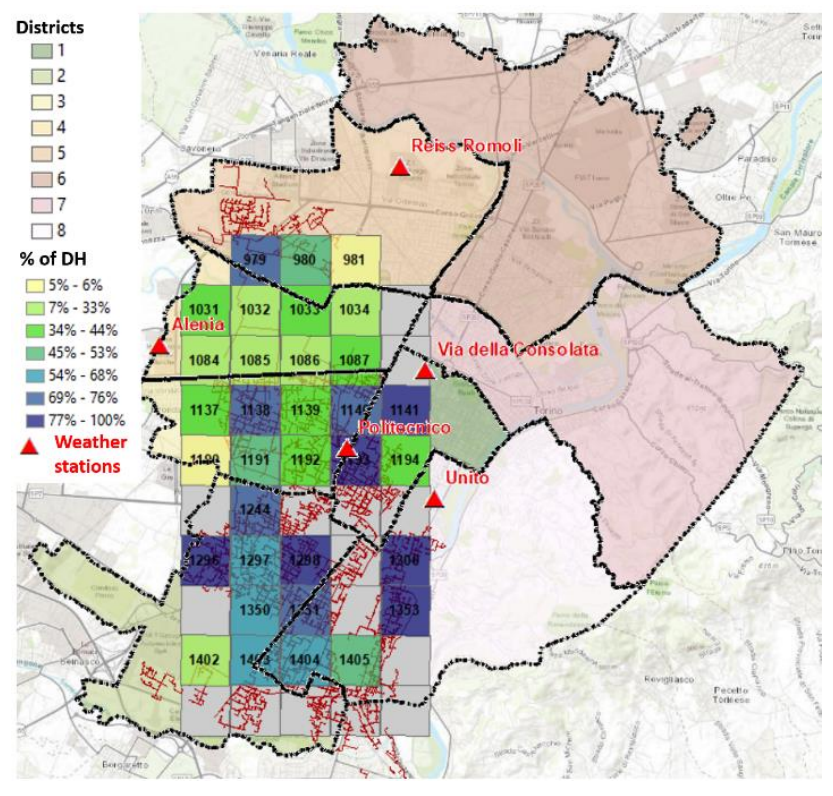

Figure 5. The case study of Turin with information on the DH network (in red) and the \% of buildings connected to the

$\mathrm{DH}$ at a mesh scale; the 8 districts are outlined in black

In this context, an urban energy balance model was applied, taking into account the characteristics of the buildings, but also of the several territorial, environmental, technical and economic constraints which influence, for example, the potential expansion of the DH network in the city. Figure 5 shows the city of Turin with information on the DH network (in red) and the forty-eight $1 \mathrm{~km}^{2}$ meshes that were categorized using the percentage of buildings connected to the DH network. Owing to a lack of data and information, only the data of the 33 colored meshes were used in this work to implement the urban energy model.

\subsection{Study area}

In order to improve energy sustainability in such a complex urban context, it is necessary to optimize the DH network. The $\mathrm{DH}$ in Turin is continuously evolving, and the data supplied by the DH company show that the network was serving about $60 \mathrm{Mm}^{3}$ in January 2016 through a complex network of over 
$500 \mathrm{~km}$ and with 5,700 heat exchange substations [28].

Through the analysis of the DH energy consumption, a 'topdown engineering' model was applied and validated at a district scale (on 33 different $1 \mathrm{~km}^{2}$ meshes). On the basis of the results of a previous research [25], seven meshes were excluded from this analysis due to the specific characteristics of some meshes that would have affected the accuracy of the model (gray meshes in Figure 5).

Table 1. Characteristics of the buildings served by the DH network at a 'mesh' level (1 x $1 \mathrm{~km})$

\begin{tabular}{|c|c|c|c|c|c|c|c|c|}
\hline $\begin{array}{c}\text { ID } \\
\text { mesh }\end{array}$ & $\begin{array}{c}\text { No of } \\
\text { buildings }\end{array}$ & $\begin{array}{c}V \\
m^{3} / 1000 \\
\end{array}$ & $\begin{array}{c}\% \\
\text { Res. }\end{array}$ & $\begin{array}{c}\% \\
\text { Mun. }\end{array}$ & $\begin{array}{c}\% \\
\text { Ter. }\end{array}$ & $\begin{array}{c}\% \\
\text { Ind. }\end{array}$ & $\begin{array}{c}\% \\
\text { DH }\end{array}$ & $\begin{array}{c}\% \\
\text { DHW }\end{array}$ \\
\hline 979 & 61 & 779 & 64.3 & 5.2 & 19.8 & 10.8 & 75.6 & 15 \\
\hline 980 & 352 & 1463 & 69.6 & 10.2 & 18.1 & 2.0 & 52.9 & 7 \\
\hline 981 & 831 & 2511 & 76.8 & 7.7 & 13.0 & 2.4 & 6.0 & 0 \\
\hline 1031 & 282 & 800 & 77.2 & 5.6 & 0.3 & 16.8 & 37.2 & 0 \\
\hline 1032 & 211 & 684 & 81.6 & 9.5 & 0.1 & 8.9 & 22.1 & 0 \\
\hline 1033 & 294 & 889 & 76.5 & 5.3 & 7.5 & 10.7 & 29.1 & 0 \\
\hline 1034 & 481 & 2087 & 56.8 & 5.3 & 33.6 & 4.2 & 25.6 & 0 \\
\hline 1084 & 688 & 2338 & 77.1 & 8.4 & 5.2 & 9.3 & 28.8 & 17 \\
\hline 1085 & 1081 & 4197 & 89.0 & 5.0 & 1.6 & 4.4 & 32.0 & 11 \\
\hline 1086 & 1129 & 4486 & 89.9 & 8.0 & 1.1 & 1.0 & 29.0 & 04 \\
\hline 1087 & 1110 & 5885 & 86.3 & 8.7 & 4.0 & 1.0 & 35.8 & 04 \\
\hline 1137 & 571 & 2553 & 82.3 & 5.7 & 4.6 & 7.4 & 44.5 & 11 \\
\hline 1138 & 646 & 4348 & 80.5 & 4.9 & 4.9 & 9.7 & 73.8 & 8 \\
\hline 1139 & 1256 & 4614 & 88.5 & 8.2 & 2.1 & 1.2 & 39.8 & 12 \\
\hline 1140 & 520 & 3092 & 68.0 & 17.2 & 14.2 & 0.6 & 74.6 & 6 \\
\hline 1141 & 47 & 133 & 48.1 & 43.9 & 5.8 & 2.2 & 100 & 9 \\
\hline 1190 & 282 & 991 & 83.9 & 6.2 & 0.9 & 9.1 & 5.1 & 0 \\
\hline 1191 & 297 & 1901 & 70.9 & 10.5 & 2.5 & 16.0 & 48.0 & 18 \\
\hline 1192 & 965 & 3508 & 78.9 & 8.5 & 6.2 & 6.4 & 42.6 & 5 \\
\hline 1193 & 636 & 3743 & 68.5 & 11.6 & 18.8 & 1.0 & 87.1 & 0 \\
\hline 1194 & 857 & 4482 & 85.2 & 12.2 & 2.3 & 0.4 & 36.7 & 3 \\
\hline 1244 & 440 & 2719 & 79.2 & 13.0 & 3.0 & 4.7 & 70.9 & 0 \\
\hline 1296 & 171 & 2172 & 86.0 & 8.4 & 2.8 & 2.7 & 100 & 11 \\
\hline 1297 & 500 & 3593 & 91.4 & 4.2 & 1.1 & 3.3 & 63.8 & 0 \\
\hline 1298 & 419 & 3033 & 81.9 & 11.9 & 4.1 & 2.1 & 100 & 24 \\
\hline 1300 & 480 & 3161 & 65.2 & 5.8 & 23.8 & 5.2 & 98.4 & 4 \\
\hline 1350 & 275 & 1610 & 53.7 & 3.7 & 0.4 & 42.2 & 63.6 & 13 \\
\hline 1351 & 416 & 3045 & 78.0 & 12.8 & 5.9 & 3.2 & 73.3 & 3 \\
\hline 1353 & 377 & 1959 & 63.8 & 4.6 & 30.5 & 1.1 & 100 & 17 \\
\hline 1402 & 60 & 504 & 29.1 & 4.7 & 0.5 & 65.7 & 27.4 & 0 \\
\hline 1403 & 229 & 1573 & 43.6 & 1.9 & 1.7 & 52.7 & 66.0 & 4 \\
\hline 1404 & 303 & 2338 & 76.6 & 9.5 & 5.5 & 8.4 & 68.4 & 4 \\
\hline 1405 & 341 & 1602 & 36.5 & 9.6 & 49.9 & 3.9 & 50.3 & 0 \\
\hline
\end{tabular}

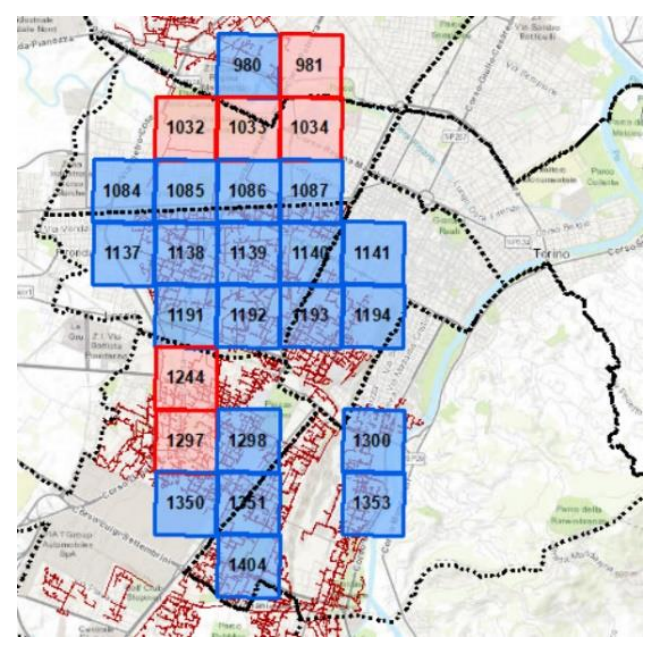

Figure 6. The 26 meshes analyzed in this work and the type of energy consumptions ('H' or 'H+DHW')
Table 1 gives information on each mesh regarding the number of buildings, a distribution of the type of users, the percentage of buildings connected to the $\mathrm{DH}$ network and the percentage of domestic hot water (DHW) on the total consumption $(\mathrm{H}+\mathrm{DHW})$. The number of buildings, the percentage of users connected to the DH network and the type of users can in particular influence the precision of the model. For example, mesh '979' mainly has industrial buildings and has only 61 buildings; meshes '1031', '1190' and '1296' have a few buildings and/or a low percentage of buildings served by DH; meshes '1402', '1403' and '1405' mainly have industrial buildings and/or only a few buildings (Table 1 and Figure 1).

\subsection{Aggregation of districts}

In order to evaluate how different scales can influence the accuracy of the energy consumption model, various mesh aggregations of different dimensions were tested. Starting from a neighborhood scale of twenty-six 1 x $1 \mathrm{~km}$ meshes, various mesh aggregations of different dimensions were tested. To do this analysis, the 26 meshes were first grouped together considering the energy consumption characteristics (scale 0), albeit only for space heating ' $\mathrm{H}$ ' and for space heating and domestic hot water ' $\mathrm{H}+\mathrm{DHW}$ ',

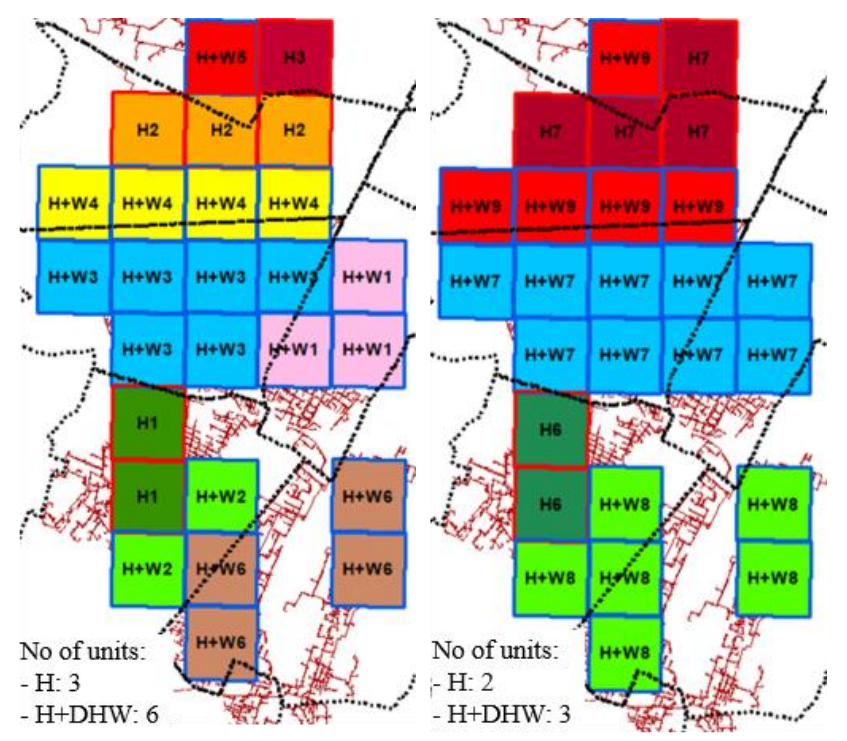

Figure 7. Mesh aggregation: a) scale 1 and b) scale 2

The second aggregation (scale 1) refers to the localization and the characteristics of the built environment and socioeconomic conditions. In order to take into account these parameters, this aggregation was made by grouping the meshes in the eight districts of Turin that have similar socioeconomic and urban characteristics. As can be seen in Figure 5 , the DH meshes only concern 6 districts of the city. As there were only a few meshes for some districts, the districts were grouped into twos; then, in scale 2, the meshes were grouped into only 3 zones of the city. Finally, in scale 3, the meshes were only grouped according to the type of energy consumption: $\mathrm{H}$ or $\mathrm{H}+\mathrm{DHW}$ (as in Figure 6). Figure 7 shows the application of the model at scales 1 and 2 ("W" means "DHW").

\subsection{Analysis of the district heating (DH) data}

The DH data provided by the IREN Company refer to the 
heated volumes and the monthly energy consumption for space heating and domestic hot water from October 2012 to January 2016. A consistent quota of residential buildings was found in most of the districts ( $1 \times 1 \mathrm{~km}$ meshes), and the model was therefore studied for this type of user as a high percentage of residential buildings are connected to the DH network (see Table 1). Two types of energy balance models were applied, on the basis of the type of consumption: one only for heating, ' $\mathrm{H}$ ', and the other for heating and domestic hot water, 'H+DHW'. The space heating and domestic hot water consumption group (H+DHW) had 20 meshes and the second one, referring to only consumption for space heating $(\mathrm{H})$, was composed of 6 meshes (see Figure 7). Data on energy consumption were available for each mesh and for three consecutive heating seasons: 2012-13, 2013-14 and 2014-15. However, only the last two heating seasons were used to validate the model because of a lack of data and anomalies in the other one (also because of the expansion of the DH network).

Table 2. Percentage of heated volume according to the period of construction (scale ' 1 ')

\begin{tabular}{|c|c|c|c|c|c|c|c|c|c|c|}
\hline \multirow{3}{*}{ Period } & \multicolumn{10}{|c|}{ Scale 1 } \\
\cline { 2 - 12 } & \multicolumn{1}{|c|}{} & $\mathbf{3}$ & \multicolumn{6}{|c|}{ H } \\
\cline { 2 - 12 } & $\mathbf{1}$ & $\mathbf{2}$ & $\mathbf{3}$ & $\mathbf{4}$ & $\mathbf{6}$ & $\mathbf{1}$ & $\mathbf{2}$ & $\mathbf{3}$ & $\mathbf{4}$ \\
\hline$>1918$ & 19 & 0 & 2 & 8 & 0 & 1 & 0 & 6 & 0 & 2 \\
\hline $1919-45$ & 36 & 3 & 16 & 20 & 1 & 12 & 5 & 10 & 5 & 14 \\
\hline $1946-60$ & 16 & 13 & 20 & 32 & 15 & 18 & 16 & 24 & 32 & 25 \\
\hline $1961-70$ & 20 & 25 & 28 & 27 & 29 & 31 & 41 & 33 & 45 & 34 \\
\hline $1971-80$ & 7 & 40 & 20 & 7 & 27 & 20 & 27 & 17 & 8 & 15 \\
\hline $1981-90$ & 1 & 14 & 4 & 2 & 20 & 11 & 4 & 3 & 0 & 5 \\
\hline $1991-00$ & 0 & 2 & 5 & 1 & 7 & 3 & 3 & 2 & 0 & 1 \\
\hline $2001-05$ & 0 & 3 & 3 & 2 & 0 & 3 & 4 & 2 & 3 & 4 \\
\hline$<2006$ & 1 & 0 & 2 & 1 & 1 & 1 & 0 & 3 & 7 & 0 \\
\hline
\end{tabular}

Table 3. Percentage of heated volume according to the period of construction (scales ' 2 ' and ' 3 ')

\begin{tabular}{|c|c|c|c|c|c|c|c|c|}
\hline \multirow{2}{*}{ Period } & \multicolumn{7}{|c|}{ Scale 2 } & \multicolumn{3}{c|}{ Scale 3 } \\
\cline { 2 - 9 } & \multicolumn{3}{|c|}{ H+W } & $\mathbf{6}$ & $\mathbf{H}$ & $\mathbf{H}$ \\
\cline { 2 - 9 } & $\mathbf{7}$ & $\mathbf{8}$ & $\mathbf{9}$ & $\mathbf{5}$ & $\mathbf{6}$ & $\mathbf{7}$ & $\mathbf{1 0}$ & $\mathbf{8}$ \\
\hline$>1918$ & 7 & 1 & 7 & 1 & 1 & 4 & 7 & 3 \\
\hline $1919-45$ & 22 & 8 & 18 & 11 & 7 & 8 & 23 & 7 \\
\hline $1946-60$ & 19 & 16 & 30 & 42 & 18 & 27 & 27 & 27 \\
\hline $1961-70$ & 25 & 28 & 27 & 31 & 40 & 37 & 23 & 33 \\
\hline $1971-80$ & 16 & 28 & 9 & 7 & 24 & 14 & 10 & 17 \\
\hline $1981-90$ & 3 & 12 & 4 & 2 & 4 & 2 & 4 & 2 \\
\hline $1991-00$ & 3 & 3 & 2 & 4 & 2 & 2 & 2 & 2 \\
\hline $2001-05$ & 2 & 3 & 1 & 3 & 4 & 2 & 2 & 3 \\
\hline$<2006$ & 2 & 1 & 1 & 0 & 0 & 4 & 2 & 5 \\
\hline
\end{tabular}

Table 2 and Table 3 show the percentage in volume of residential buildings at different scales according to the period of construction. This analysis made it possible to calculate some input data, such as the thermal transmittances, the envelope thickness, the window characteristics and the efficiencies of the systems, for each area to simulate the energy consumptions. As it is possible to observe, most of the residential buildings in Turin were built between 1946 and 1970 , but the percentages change when the different scales are considered.

\section{RESULTS AND DISCUSSION}

The 'top-down' engineering model presented in this work was set up for residential buildings, and its field of application is therefore mainly residential districts. From this work, it has emerged that the accuracy of the models depends on: the distribution of the type of users (percentage and number of residential buildings), the percentage of heated volumes connected to the DH network and the dimensions of the used territory unit (i.e. scale $0,1,2$ or 3 ).

\subsection{The urban energy balance models}

Starting from a previous research [25], an implemented urban energy balance model was created using the DH data. In the model presented for residential buildings, the space heating and domestic hot water consumptions were simulated using a 'top-down engineering' approach considering groups of buildings with different dimensions and two urban parameters: $\mathrm{H} / \mathrm{W}$ and SVF. In the energy balance model, all the variables refer to the relative mesh with average or total values.

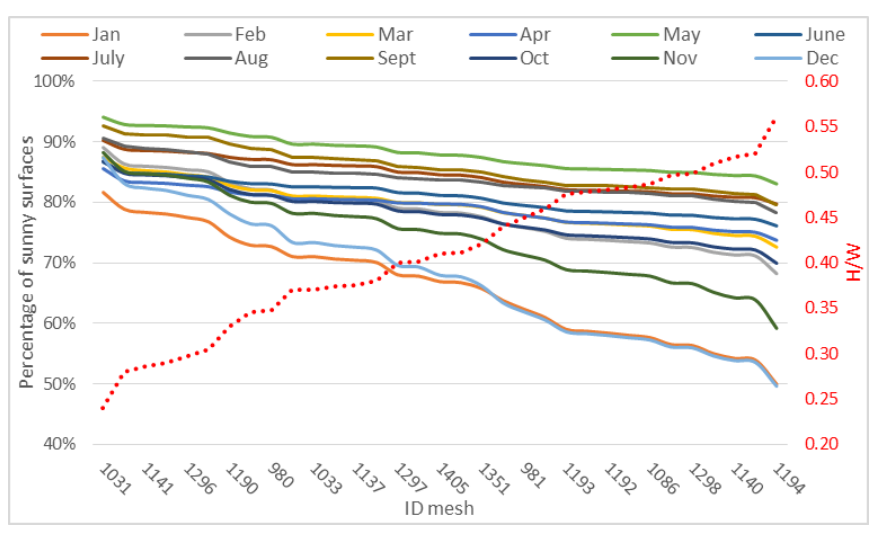

Figure 8. Percentage of monthly sunny surfaces calculated for each mesh with method a) considering the $\mathrm{H} / \mathrm{W}$

According to section 2.1.1, the percentage of sunny surfaces used to calculate the solar heat gains was evaluated using the average height, the position of the sun for each month and the canyon height-to-distance ratio $\mathrm{H} / \mathrm{W}$. Figure 8 shows the percentage of sunny surfaces for each month for the 33 analyzed meshes. It is possible to observe that during some of the winter months (such as December and January), the quota of sunny surfaces is lower and, more generally, the quota of sunny surfaces is inversely proportional to the $\mathrm{H} / \mathrm{W}$ ratio. For example, meshes 1031 and 1141 have an average building height of 11-13 m, while meshes 1140 and 1194 have an average building height of 17-20 m; this means that, for the same month, a high building density corresponds to lower solar gains.

Different types of errors were considered to evaluate the accuracy of the model by changing the application scale. The relative $\mathrm{E}_{\mathrm{r}}$, absolute relative $\left|\mathrm{E}_{\mathrm{r}}\right|$ and global relative $\mathrm{E}_{\mathrm{r}, \mathrm{gl}}$ errors were used to compare the measured and calculated values for each month and heating season:

- $\mathrm{E}_{\mathrm{r}}$ is calculated as the difference between the measured and forecast values, divided by the measured value for a monthly time step;

- $\left|E_{\mathrm{r}}\right|$ is the absolute value of the relative error for a monthly time step; the absolute relative error is usually used to measure the prediction accuracy of the model;

- $\mathrm{E}_{\mathrm{r}, \mathrm{gl}}$ is calculated as the difference between the measured and forecast values, divided by the measured value, considering a complete heating season. 


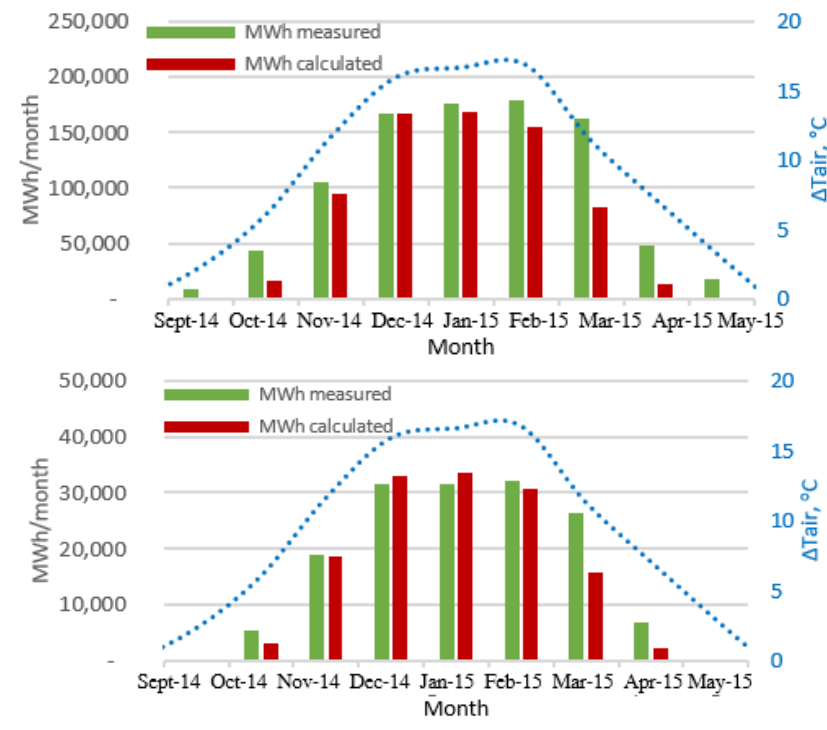

Figure 9. Comparison between the monthly measured and the forecast consumptions for the 2014-15 heating season using scale ' 3 ' (Figure 6): a) H+DHW; b) H

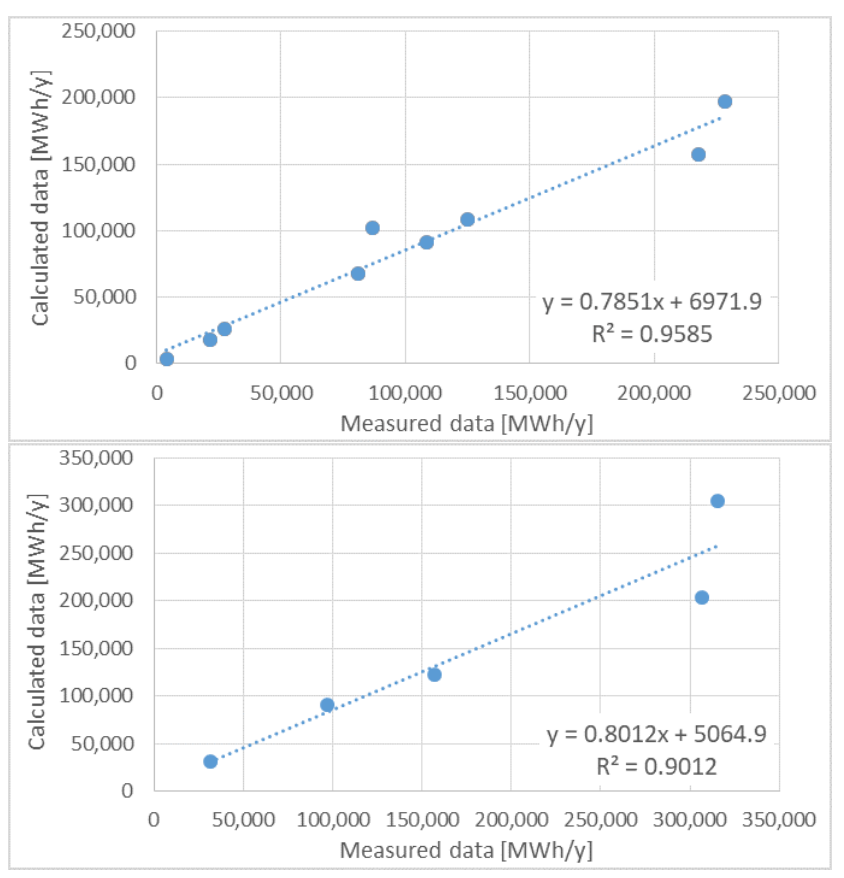

Figure 10. The calculated energy consumption values on the $\mathrm{x}$-axis were compared with the measured values on the $\mathrm{y}$ axis: a) scale ' 1 ' and b) scale ' 2 '

Figure 9 shows some examples of monthly consumptions for space heating and the domestic hot water profile at a global scale (scale ' 3 '). The energy model is quite accurate, especially during the November to March period (the heating period for the city of Turin is from October $15^{\text {th }}$ to April $15^{\text {th }}$ ).

Figure 10 compares the measured data (y-axis) with the data calculated using the energy model (x-axis). The annual consumptions (average value considering three consecutive heating seasons) are indicated for each urban area considering scales ' 1 ' and ' 2 ' (cfr. Figure 8). It is possible to observe a good correlation with the high coefficient of determination $\mathrm{R}^{2}$.

Table 4 and Table 5 show the results obtained from the application of the energy models at the different urban scales. The absolute relative error $\left(\left|\mathrm{E}_{\mathrm{r}}\right|\right)$ was mainly used to evaluate the accuracy of the energy model, because its average value is more significant, considering all the positive gaps. The global relative error $\left(\mathrm{E}_{\mathrm{r}, \mathrm{gl}}\right)$ was also considered to take into account the energy model adjustments,. The energy consumption data of the two heating seasons (2013-14 and 2014-15) were used to validate the model. From the results (Table 4 and Table 5), it has emerged that as the scale of application increases, the inaccuracy of the model tends to increase; moreover, there are some variables, such as the percentage of residential buildings and quota served by DH, that influence the accuracy of the model by offsetting the influence of the scale dimension. It was noticed that when the values of the percentage of DH and of the residential buildings increase, the results are more accurate. Considering the all 33 meshes ("all" in grey and in italics), instead excluding the seven meshes as mentioned in paragraph 3.1, it is possible to observe that the accuracy of the model decrease.

Table 4. Results: H+DHW model

\begin{tabular}{|c|c|c|c|c|c|c|c|c|}
\hline scale & $\mathrm{E}_{\mathrm{r}}[\%]$ & $\left|\mathbf{E}_{\mathrm{r}}\right|$ & or & $E_{r, g l}$ & {$[\%]$} & units & DH & $\mathbf{R e}$ \\
\hline - & \begin{tabular}{|l|lll} 
sel & all \\
\end{tabular} & sel. & all & sel. & all & & $\%$ & $\%$ \\
\hline $\mathbf{0}$ & \begin{tabular}{|l|l|}
-10 & -11 \\
\end{tabular} & 17 & 20 & -11 & -13 & $20(23)$ & 61 & 75 \\
\hline 1 & \begin{tabular}{|l|l|l|}
-12 & -16 \\
\end{tabular} & 20 & 25 & -12 & -17 & $6(6)$ & 63 & 73 \\
\hline 2 & \begin{tabular}{|l|l|}
-20 & -20 \\
\end{tabular} & 23 & 24 & -20 & -20 & $3(3)$ & 60 & 76 \\
\hline 3 & \begin{tabular}{|l|l|l|}
-16 & -18 \\
\end{tabular} & 16 & 18 & -15 & -17 & $1(1)$ & 66 & 74 \\
\hline
\end{tabular}

Table 5. Results: H model

\begin{tabular}{|c|c|c|c|c|c|c|c|c|c|}
\hline Scale & \multicolumn{2}{|c|}{$\mathbf{E}_{\mathbf{r}}[\mathbf{\%}]$} & \multicolumn{2}{|c|}{$\left|\mathbf{E}_{\mathbf{r}}\right|[\mathbf{\%}]$} & \multicolumn{2}{|c|}{$\mathbf{E}_{\mathbf{g l}}[\mathbf{\%}]$} & units & $\mathbf{D H}$ & Res. \\
\hline $\mathbf{-}$ & sel. & all & $\mathbf{\%}$ & all & $\mathbf{\%}$ & all & - & $\mathbf{\%}$ & $\mathbf{\%}$ \\
\hline $\mathbf{0}$ & -7 & -16 & 16 & 26 & -10 & -18 & $6(10)$ & 36 & 77 \\
\hline $\mathbf{1}$ & -12 & -7 & 16 & 21 & -12 & -7 & $3(5)$ & 33 & 78 \\
\hline $\mathbf{2}$ & -12 & -14 & 18 & 17 & -5 & -8 & $2(3)$ & 42 & 80 \\
\hline $\mathbf{3}$ & -10 & -11 & 15 & 14 & -9 & -10 & $1(1)$ & 42 & 80 \\
\hline
\end{tabular}

\subsection{The urban energy atlas at a territorial scale}

With the support of a GIS tool, an urban energy atlas was created using Google Earth. This urban energy atlas is a platform that can be useful to: visualize the distribution of energy consumption at different territorial scales, assess the constrains and limits on a territory and then evaluate the potential energy savings and/or low-carbon measures that boost the available renewable energy sources (RES). It is possible, with a combined use of energy consumption, production and productivity models, to evaluate future scenarios in which energy security, sustainability and affordability are improved for a more resilient city (Figure 11). According to the Sustainable Energy Action Plan (SEAP), the key actions that should be introduced to improve the energy sustainable development of Turin refer to the following topics: sustainable mobility (i.e. bike-sharing), green public procurement, and energy efficiency measures for public buildings and lighting systems. An urban energy atlas of Turin could help support these evaluations by assessing the feasibility of key actions through a cost/benefit analysis in which the energetic, economic, environmental and social aspects are considered.

In this work, the presented urban energy atlas applied energy consumption and energy saving models to all the buildings in the city of Turin; future scenarios have been hypothesized in terms of 'standard' and 'advanced' energy retrofitting measures. The energy saving models were developed with bottom-up and top-down approaches using data from Energy Performance Certificates [25]. The adopted 
energy efficiency measures consider different interventions, such as thermal insulation of the buildings envelope and/or the replacement of generation systems, considering all the constrains of the built environment and the urban context.

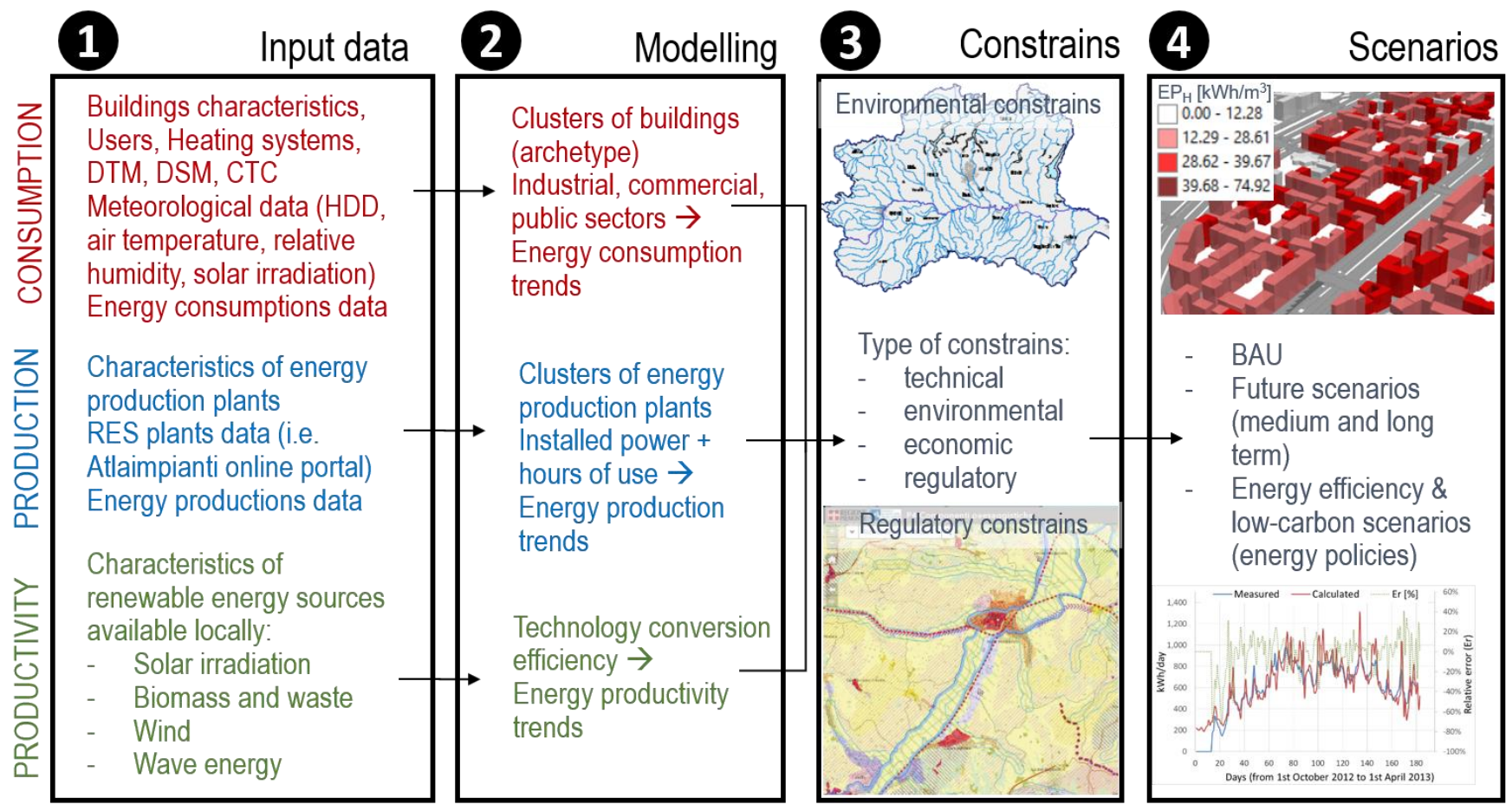

Figure 11. Energy GIS-based models: Consumption, energy production and potential energy productivity

The combined use of energy models - which assess energy consumption, production and productivity from RES - allows the demand and supply of energy for low-carbon resilient cities to be optimized. For example, by analyzing the data of energy produced by RES (Atlaimpianti portal: https://atla.gse.it/atlaimpianti/project/Atlaimpianti_Internet.h $\mathrm{tml}$ ) for the residential buildings of Turin, it emerged that $38 \%$ of the electrical consumption is covered by a waste-to-energy plant, biogas plants, photovoltaic modules, and hydro plants. A similar analysis to the one used for the solar portal of the Metropolitan City of Turin could be utilized for all the buildings to evaluate the productivity of roof-integrated solar technologies (i.e. photovoltaic modules and solar thermal collectors) (http://energia.sistemapiemonte.it/ittb-torino).
Financial mechanisms and incentives to support energy efficiency measures also have to be taken into account in economic evaluations. In Italy, the Ecobonus scheme with its tax benefits, has been extended until December 2021. This scheme could be an effective mechanism to promote the renovation of buildings.

Finally, an urban energy atlas can be a useful tool to plan strategies for a more sustainable development of the territory, in order to also help local authorities to define energy policies adapted to the real context (at a municipal scale). This atlas can also help citizens giving information on the potential of energy savings or on the energy that can be produced from RES (at a building scale or district/territorial scale).

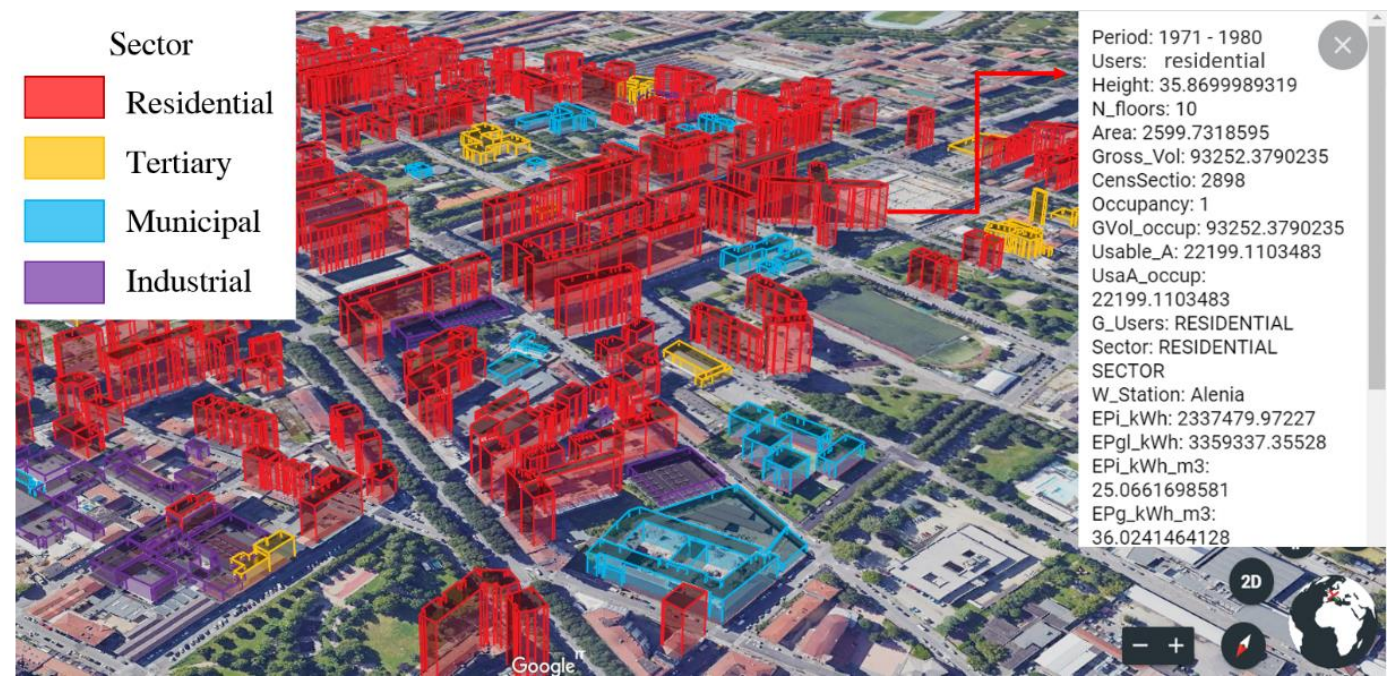

Figure 12. Building data and type of users 


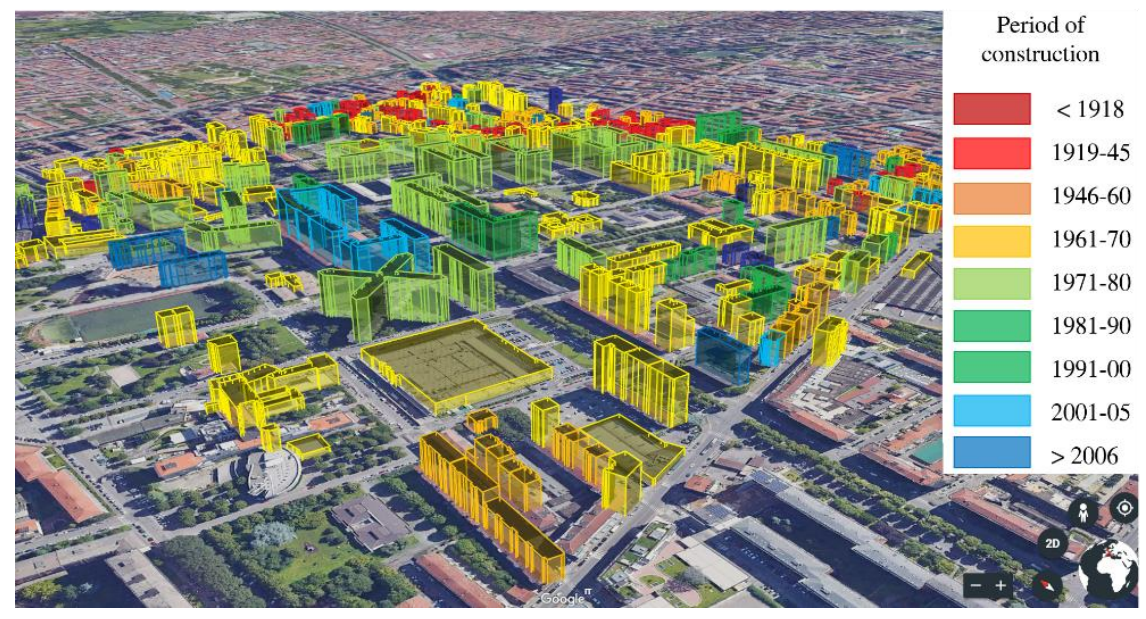

Figure 13. Classification by period of construction

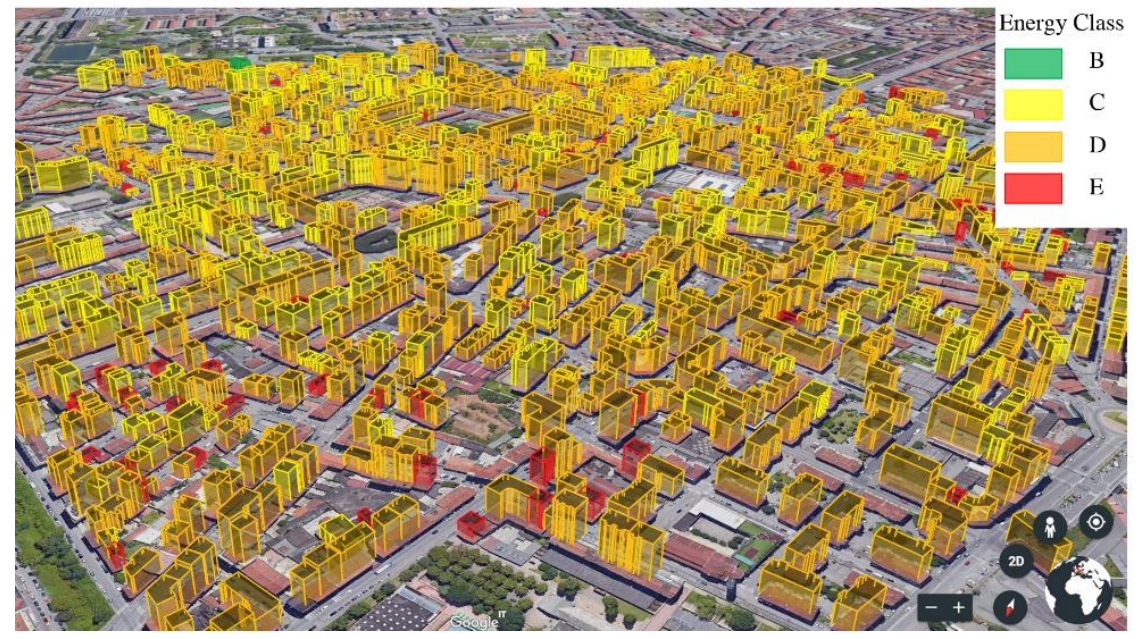

Figure 14. Energy class from the application of the annual space heating and domestic hot water models

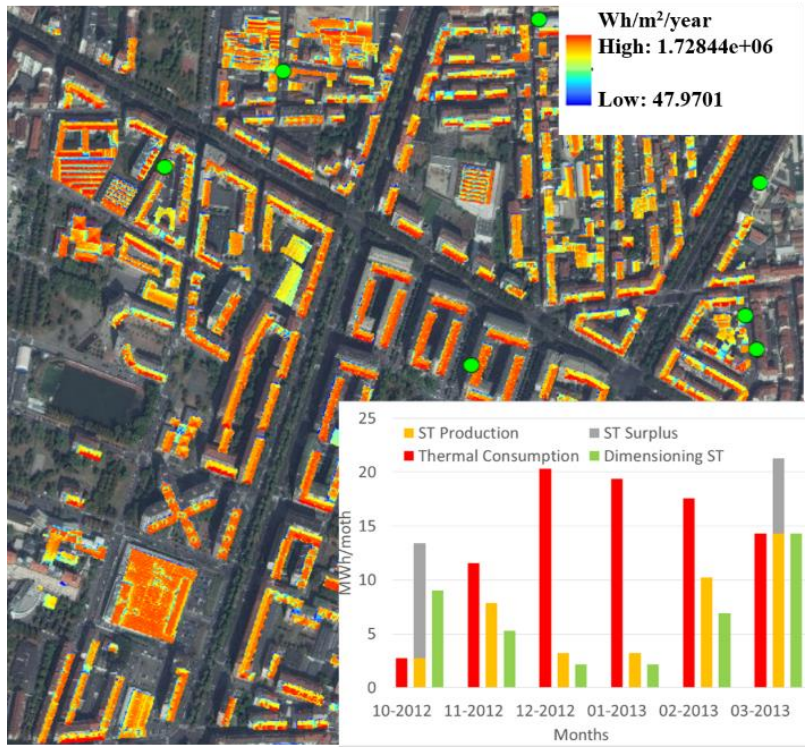

Figure 15. Solar resource, energy production and potential energy productivity

Figures 12, 13, 14 and 15 describe some outputs of the urban energy atlas that represent the characteristics of the built environment and its energy performances. Figure 12 shows the different types of information that are available at a building scale, such as the address, the type of use, the construction period, the gross and heated volume, the technological systems, the measured and simulated energy consumption, etc.

In Figures 12, 13 and 14, the buildings are classified according to:

- the type of user; as previously mentioned, it is possible to observe that the buildings in Turin are mainly of a residential type;

- the period of construction; most of the buildings in Turin were built between 1946 and 1970;

- the energy classes resulting from the presented model.

Figure 15 shows the annual solar radiation of the roofs of the residential buildings in an area of Turin. The buildings in which the solar collectors and photovoltaic modules are already present are indicated (green dots). The thermal consumptions were compared with the potential thermal production. The hypothesized solar thermal (ST) area was assessed considering the roof area that was exposed the most to the solar irradiation of the analyzed buildings. Figure 15 shows the potential thermal production from solar thermal collectors for each month (with an average annually efficiency of $60 \%$ and a system performance ratio of $75 \%$ ) for a residential building. Moreover, by applying different energy saving measures, a cost benefit analysis can identify critical or favorable/easy areas where it is convenient to realize retrofitting interventions. This tool can also be used to evaluate the available renewable energy sources and their effective potential. 


\section{CONCLUSIONS}

This work presents an engineering model applied to the case study of the city of Turin (IT). A simplified neighborhoodscale energy balance model has been applied to different territorial units of various dimensions and characteristics.

The 'engineering' model is able to predict the energy consumptions, at monthly time steps, for space heating and domestic hot water, considering from 1 to $26 \mathrm{~km}^{2}$ urban areas. The accuracy of these models depends on the distribution of the type of users, on the percentage of heated volume served by the $\mathrm{DH}$ network and on the dimension of the used territorial unit. In general, the accuracy of the model tends to decrease as the scale of application increases. However, when the percentage of residential buildings and the quota served by $\mathrm{DH}$ increase, the results are more accurate.

This model was applied to create an urban energy atlas for the building stock of the city of Turin with the support of Geographical Information System and Google Earth tools. The aim has been to create a platform to help stakeholders, urban planners and policy makers plan sustainable and smart energy systems at a territorial level, and to obtain information, at different urban levels, about the energy consumptions and all the indexes connected to the energy use.

With this engineering model, it is also possible to modify the input parameters and evaluate how energy consumption changes according to such energy related-variables as the building efficiency level and system efficiencies, but also the building density and, more generally, the urban morphology. For example, with the urban energy atlas, critical areas can be identified where constrains can limit the adoption of energy efficiency measures. In these areas, other solutions can be found to boost the available energy sources and modify the energy demand by aggregating different users or by adopting an energy balance over a larger territory with more resources (from a district, to a municipal or even a regional area). The goal is to guarantee energy security, affordability and environmental sustainability for more resilient cities.

In future researches, new indexes, based on how the energy system responds to disturbances, events or non-linear dynamics, will be investigated to evaluate future scenarios and how the system adapts.

\section{REFERENCES}

[1] Tamene, Y., Serir, L. (2019). Thermal and economic study on building external walls for improving energy efficiency. International Journal of Heat and Technology, 37(1): 219-228. https://doi.org/10.18280/ijht.370127

[2] Mutani, G., Todeschi, V., Grisolia, G., Lucia, U. (2019). Introduction to constructal law analysis for a simplified hourly energy balance model of residential buildings at district scale. TECNICA ITALIANA-Italian Journal of Engineering Science, 63(1): 13-20. https://doi.org/10.18280/ti-ijes.630102

[3] Rodrigues, E., Fernandes, M.S., Gaspar, A.R., Gomes, Á., Costa, J.J. (2019). Thermal transmittance effect on energy consumption of Mediterranean buildings with different thermal mass. Applied Energy, 252: 113437. https://doi.org/10.1016/J.APENERGY.2019.113437

[4] Wu, W. (2019). Economic analysis of energy consumption based on thermoeconomic cost analysis model. International Journal of Heat and Technology,
37(2): 620-624. https://doi.org/10.18280/ijht.370233

[5] Wang, Y., Ni, Z., Chen, S., Xia, B. (2019). Microclimate regulation and energy saving potential from different urban green infrastructures in a subtropical city. Journal of Cleaner Production, 226: 913-927. https://doi.org/10.1016/J.JCLEPRO.2019.04.114

[6] Hedegaard, R.E., Kristensen, M.H., Pedersen, T.H., Brun, A., Petersen, S. (2019). Bottom-up modelling methodology for urban-scale analysis of residential space heating demand response. Applied Energy, 242: 181-204. https://doi.org/10.1016/j.apenergy.2019.03.063

[7] Sola, A., Corchero, C., Salom, J., Sanmarti, M. (2019). Multi-domain urban-scale energy modelling tools: A review. Sustainable Cities and Society. https://doi.org/10.1016/J.SCS.2019.101872

[8] Perera, A.T.D., Coccolo, S., Scartezzini, J.L., Mauree, D. (2018). Quantifying the impact of urban climate by extending the boundaries of urban energy system modeling. Applied Energy, 222: 847-860. https://doi.org/10.1016/J.APENERGY.2018.04.004

[9] Martellotta, F., Cannavale, A., Ayr, U. (2019). A machine learning approach to predict energy consumptions in office and industrial buildings as a function of weather data. TECNICA ITALIANA-Italian Journal of Engineering Science, 63(2-4): 452-458. https://doi.org/10.18280/ti-ijes.632-449

[10] Kristensen, M.H., Hedegaard, R.E., Petersen, S. (2018). Hierarchical calibration of archetypes for urban building energy modeling. Energy and Buildings, 175: 219-234. https://doi.org/10.1016/j.enbuild.2018.07.030

[11] Nageler, P., Zahrer, G., Heimrath, R., Mach, T., Mauthner, F., Leusbrock, I., Schranzhofer, H., Hochenauer, C. (2017). Novel validated method for GIS based automated dynamic urban building energy simulations. $\quad$ Energy, 139: 142-154. https://doi.org/10.1016/J.ENERGY.2017.07.151

[12] Yang, F., Chen, L. (2016). Developing a thermal atlas for climate-responsive urban design based on empirical modeling and urban morphological analysis. Energy and Buildings, 111: 120-130. https://doi.org/10.1016/J.ENBUILD.2015.11.047

[13] Pazúr, R., Feranec, J., Štych, P., Kopecká, M., Holman, L. (2017). Changes of urbanised landscape identified and assessed by the Urban Atlas data: Case study of Prague and Bratislava. Land Use Policy, 61: 135-146. https://doi.org/10.1016/J.LANDUSEPOL.2016.11.022

[14] Johansson, T., Olofsson, T., Mangold, M. (2017). Development of an energy atlas for renovation of the multifamily building stock in Sweden. Applied Energy, 203: 723-736. https://doi.org/10.1016/J.APENERGY.2017.06.027

[15] Petrovic, S., Karlsson, K. (2016). Ringkøbing-Skjern energy atlas for analysis of heat saving potentials in building stock. Energy, 110: 166-177. https://doi.org/10.1016/J.ENERGY.2016.04.046

[16] Andresen, G.B., Søndergaard, A.A., Greiner, M. (2015). Validation of Danish wind time series from a new global renewable energy atlas for energy system analysis. Energy, 93: 1074-1088. https://doi.org/10.1016/J.ENERGY.2015.09.071

[17] Ashfaq, A., Ianakiev, A. (2018). Features of fully integrated renewable energy atlas for Pakistan; wind, solar and cooling. Renewable and Sustainable Energy Reviews,

97:

14-27. 
https://doi.org/10.1016/J.RSER.2018.08.011

[18] Alhamwi, A., Medjroubi, W., Vogt, T., Agert, C. (2017). GIS-based urban energy systems models and tools: Introducing a model for the optimisation of flexibilisation technologies in urban areas. Applied Energy, 191: 1-9. https://doi.org/10.1016/J.APENERGY.2017.01.048

[19] Zou, J., Chang, Q., Ou, X., Arinez, J., Xiao, G. (2019). Resilient adaptive control based on renewal particle swarm optimization to improve production system energy efficiency. Journal of Manufacturing Systems, 50: 135-145. https://doi.org/10.1016/J.JMSY.2018.12.007

[20] Kishita, Y., McLellan, B.C., Giurco, D., Aoki, K., Yoshizawa, G., Handoh, I.C. (2017). Designing backcasting scenarios for resilient energy futures. Technological Forecasting and Social Change, 124: 114125. https://doi.org/10.1016/J.TECHFORE.2017.02.001

[21] Mutani, G., Todeschi, V. (2018). Energy resilience, vulnerability and risk in urban spaces. Journal of Sustainable Development of Energy, Water and Environment Systems, 6(4): 694-709. https://doi.org/10.13044/J.SDEWES.D6.0211

[22] Bertheau, P., Blechinger, P. (2018). Resilient solar energy island supply to support SDG7 on the Philippines: Techno-economic optimized electrification strategy for small islands. Utilities Policy, 54: 55-77. https://doi.org/10.1016/J.JUP.2018.07.005

[23] Baniassadi, A., Heusinger, J., Sailor, D.J. (2018). Energy efficiency vs resiliency to extreme heat and power outages: The role of evolving building energy codes. Buildng and Environment, 139: 86-94. https://doi.org/10.1016/J.BUILDENV.2018.05.024

[24] Bagheri, M., Delbari, S.H., Pakzadmanesh, M., Kennedy, C.A. (2019). City-integrated renewable energy design for low-carbon and climate-resilient communities. Applied Energy, 239: 1212-1225. https://doi.org/10.1016/J.APENERGY.2019.02.031

[25] Mutani G., Todeschi V., Coors V., Kaempf J., Fitzky M. (2018). Building energy consumption modeling at urban scale: Three case studies in Europe. INTELEC $® 2018$ International Telecommunications Energy Conference Proceedings.

https://doi.org/10.1109/INTLEC.2018.8612382

[26] Mutani, G., Todeschi, V. (2017). Space heating models at urban scale for buildings in the city of Turin (Italy). Energy Procedia, 122: 841-846. https://doi.org/10.1016/j.egypro.2017.07.445

[27] TABULA. (2012). Typology Approach for Building Stock Energy Assessment - TABULA. Intelligent Energy Europe (IEE).

[28] Guelpa, E., Mutani, G., Todeschi, V., Verda, V. (2017). A feasibility study on the potential expansion of the district heating network of Turin. Energy Procedia, 122: 847-852. https://doi.org/10.1016/j.egypro.2017.07.446

\section{NOMENCLATURE}

\begin{tabular}{|c|c|c|}
\hline Symbol & Quantity & Unit \\
\hline A & Area & $\mathrm{m}^{2}$ \\
\hline DH & District heating & - \\
\hline DHW & Domestic hot water & \\
\hline DSM & Digital Surface Model & - \\
\hline $\mathrm{Er}$ & Relative error & $\%$ \\
\hline $\mathrm{F}$ & Reduction factor & - \\
\hline $\mathrm{g}$ & Total solar energy transmittance & - \\
\hline GIS & Geographic Information System & - \\
\hline $\mathrm{H}$ & $\begin{array}{l}\text { Heat transfer coefficient and space } \\
\text { heating }\end{array}$ & $\mathrm{W} / \mathrm{K}(-)$ \\
\hline HDD & Heating Degree Days & ${ }^{\circ} \mathrm{C}$ \\
\hline $\mathrm{H} / \mathrm{W}$ & Canyon effect & $\mathrm{m} / \mathrm{m}$ \\
\hline $\mathrm{h}$ & Heat transfer surface coefficient & $\mathrm{W} / \mathrm{m}^{2} / \mathrm{K}$ \\
\hline I & Solar irradiance & $\mathrm{W} / \mathrm{m}^{2}$ \\
\hline Q & Energy & $\mathrm{Wh}$ \\
\hline $\mathrm{R}$ & Thermal resistance & $\mathrm{m}^{2} \mathrm{~K} / \mathrm{W}$ \\
\hline S & Net heated area & $\mathrm{m}^{2}$ \\
\hline $\mathrm{S} / \mathrm{V}$ & Surface-to-volume ratio & $\mathrm{m}^{2} / \mathrm{m}^{3}$ \\
\hline SVF & Sky view factor & - \\
\hline $\mathrm{T}$ & Air temperature & ${ }^{\circ} \mathrm{C}, \mathrm{K}$ \\
\hline $\mathrm{U}$ & Thermal transmittance & $\mathrm{W} / \mathrm{m}^{2} / \mathrm{K}$ \\
\hline $\mathrm{V}$ & Volume & $\mathrm{m}^{3}$ \\
\hline $\mathrm{W}$ & Domestic hot water & - \\
\hline WS & Weather station & - \\
\hline$\alpha$ & Solar radiation absorption coefficient & - \\
\hline$\beta$ & Solar height & \\
\hline$\varepsilon$ & Emissivity of a surface & - \\
\hline$\omega$ & Percentage of sunny surfaces & - \\
\hline$\eta$ & $\begin{array}{l}\mathrm{H} \text { and DHW efficiency, utilization } \\
\text { factor }\end{array}$ & - \\
\hline$\rho$ & Density & $\mathrm{kg} / \mathrm{m}^{3}$ \\
\hline$\Sigma$ & Surface inclination & ${ }^{\circ}, \mathrm{rad}$ \\
\hline$\tau$ & Number of hours & $\mathrm{h}$ \\
\hline$\Phi$ & Heat flow rate, thermal power & $\mathrm{W}$ \\
\hline
\end{tabular}

\section{Subscripts}

$\begin{array}{llll}\text { a } & \text { air } & \text { int } & \text { internal heat gains } \\ \text { adj } & \text { adjusted } & \text { nd } & \text { needs } \\ \text { avg } & \text { average } & \text { ob } & \text { obstacles } \\ \text { DHW } & \text { domestic hot water } & \text { op } & \text { opaque } \\ \text { e } & \text { external } & \text { r } & \text { radiative } \\ \text { F } & \text { frame } & \text { se } & \text { external surface } \\ \text { f } & \text { floor } & \text { sh } & \text { shading } \\ \text { g } & \text { ground } & \text { sol } & \text { solar } \\ \text { gl } & \text { glazing, glazed element } & \text { tr } & \text { transmission } \\ \text { gn } & \text { gains } & \text { v } & \text { volume } \\ \text { ht } & \text { heat transfer } & \text { ve } & \text { ventilation } \\ \text { H } & \text { heating } & \text { w } & \text { window } \\ \text { i } & \text { internal } & \text { W } & \text { domestic hot water }\end{array}$

